\title{
ESwab challenges influenza virus propagation in cell cultures
}

R Trebbien (ratr@ssi.dk) ${ }^{1}$, B Andersen ${ }^{1}$, J Rønn¹, J McCauley², T Kølsen Fischer ${ }^{1}$

1. National Influenza Center Denmark, Statens Serum Institut, Copenhagen, Denmark

2. WHO Collaborating Centre for Reference and Research on Influenza, Division of Virology, MRC National Institute for Medical Research, London, United Kingdom

Citation style for this article:

Trebbien R, Andersen B, Rønn J, McCauley J, Kølsen Fischer T. ESwab challenges influenza virus propagation in cell cultures. Euro Surveill. 2014;19(50):pii=20995. Available online: http://www.eurosurveillance.org/ViewArticle.aspx?Articleld=20995

Article submitted on 01 December 2014 / published on 18 December 2014

Although the ESwab kit (Copan, Brescia, Italy) is intended for sampling bacteria for culture, this kit is increasingly also used for virus sampling. The effect of ESwab medium on influenza virus detection by realtime reverse transcription-polymerase chain reaction (RT-PCR) or virus propagation in Madin-Darby canine kidney (MDCK) cell culture was investigated. The ESwab medium was suitable for viral RNA detection but not for viral propagation due to cytotoxicity. Sampling influenza viruses with ESwab challenges influenza surveillance by strongly limiting the possibility of antigenic characterisation.

\section{Background}

Viral culture is a prerequisite for the surveillance of antigenic drift of influenza viruses as well as phenotypic antiviral resistance [1,2]. Antigenic drift of influenza virus can result in severe epidemics and vaccine failure, with consequences for especially the risk groups who are recommended the seasonal influenza vaccine [3]. Monitoring changes in the phenotypic traits of influenza virus is therefore an important component of the international and national surveillance systems.

At the National Influenza Center (NIC) in Denmark, we have experienced challenges during the recent 2012/13 and 2013/14 seasons with culture of influenza virus in clinical samples submitted from regional hospitals. Atypical cytopathogenic effect (CPE)/cytotoxicity in cell cultures appear for clinical materials which have been sampled using the ESwab sampling kit (ESwab, Copan, Brescia, Italy). The medium included in the sampling kit is modified Amies medium intended for bacterial culture and is not recommended for virus isolation by the manufacturer [4-6].

According to the feedback that the Danish NIC has received from the clinical microbiology laboratories, the ESwab kit is increasingly popular for multipurpose sampling due to the ease of use and low cost. The sampling kit is useful for analysing both bacterial and virus samples for diagnostic purposes using polymerase chain reaction (PCR) techniques $[7,8]$. Studies of cell propagation of influenza virus stored in the ESwab sampling kit have only been reported in one previous study by Indevuyst et al. [9], who describe that atypical CPE can be attributed to the flocked swab included in the kit. However, the swab alone cannot explain the widespread atypical CPE we have observed, and to explore this further we have studied the effect of ESwab's modified Amies medium directly onto MadinDarby canine kidney (MDCK) cell culture as well as the effect on virus propagation. The suitability of ESwab medium for influenza virus detection by realtime reverse transcription-polymerase chain reaction (RT-PCR) was also investigated.

\section{Methods}

\section{Testing ESwab medium suitability for viral culture}

Twenty ESwab medium solutions were each used as a starting point to generate twofold dilution series in replicate of ESwab medium (without the swab) in Eagles minimum essential medium (MEM). The dilution ranged from undiluted to 1:128. Three different batches of the medium were used in the experiments to exclude lot variation. Pure Eagles MEM was used as negative control for each ESwab dilution series. Once established all dilutions and controls were stored at $4^{\circ} \mathrm{C}$ for 24 hours before being tested for their effect on MDCK cells.

To test the effect of pure ESwab medium and the diluted ESwab medium solutions described above on MDCK cells, these solutions as well as negative controls were respectively inoculated on the cells. The degree of cytotoxicity was evaluated by scoring from 0 to 5 , where o was no cytotoxicity, 1 was low and 5 was extensive cytotoxicity. 
Cytotoxic effect observed in Madin-Darby canine kidney cell cultures inoculated with solutions consisting of varying proportions of ESwab and Eagles minimum essential media

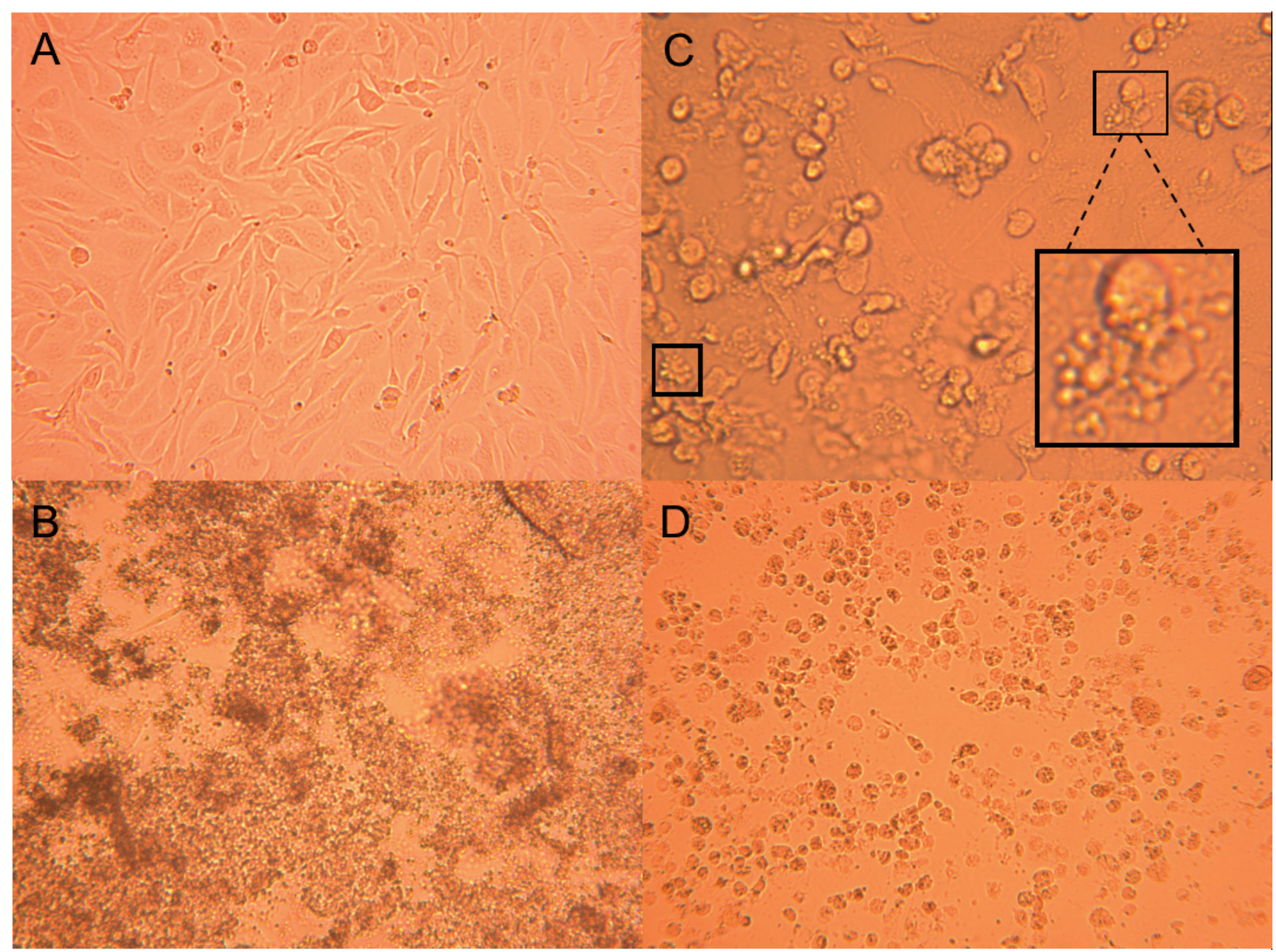

MDCK: Madin-Darby canine kidney cells.

A: Negative MDCK cell control inoculated with pure Eagles minimum essential medium after 24 hours of incubation, magnification $\times 20$, B: MDCK cells inoculated with pure ESwab medium after 24 hours of incubation, magnification $\times 20$, C: MDCK cells inoculated with ESwab diluted 1:2 in Eagles minimum essential medium after 24 hours of incubation. Black squares indicate apoptotic cells surrounded by apoptotic bodies. One of the squares is magnified (x60) to enhance visibility of apoptotic bodies surrounding a degenerated cell, magnification X20 D: MDCK cells inoculated with influenza virus ( $\mathrm{H}_{1} \mathrm{~N}_{1} \mathrm{pdmog}$ ), rounded cells typical for influenza virus cytopathogenic effect are visible, magnification $x 10$.

To evaluate the direct effect of ESwab medium and diluted ESwab medium solutions on virus propagation, reference virus isolates as well as virus isolates from clinical samples were respectively diluted 10 -fold in these solutions. The reference virus isolates were A/California/07/2009 (H1N1pdmo9) (passage history: two times in primary swine kidney cells (sw)/four times in MDCK (2sw/4MDCK)), A/Denmark/42/2014 $\left(\mathrm{H}_{1} \mathrm{~N}_{1}\right)$ (2MDCK), A/Brisbane/10/2007( $\mathrm{H}_{3} \mathrm{~N}_{2}$ ) (3MDCK), and A/Denmark/43/2014 ( $\left.\mathrm{H}_{3} \mathrm{~N}_{2}\right)$ (2MDCK-SIAT/1MDCK). Identical virus dilutions were also made in Eagles MEM as controls. Negative controls of pure Eagles MEM were also included.

Dilutions were stored at $4^{\circ} \mathrm{C}$ for 24 hours before inoculation following normal procedures in confluent monolayers of MDCK cells. The cells were observed daily and CPE was scored from o to 4, where o was no CPE, 1 was up to $25 \%$ CPE, 2: $25-50 \%$, 3: $50-75 \%$ and 4: $75-100 \%$ CPE. Cell cultures were fixed and immunostained for influenza virus after 48 hours. Cell cultures were considered influenza positive if characteristic influenza virus CPE appeared and if the cells were positive for influenza virus by immunostaining.

\section{Testing ESwab medium for real-time reverse transcription-polymerase chain reaction} In order to confirm the suitability of virus samples submitted in ESwab medium for diagnostics using PCR technology, H1N1pdmog virus was subjected to a tenfold dilution series either in ESwab medium or in phosphate-buffered saline (PBS). The viral solutions obtained were tested by two in-house real-time reverse transcription (RT)-PCR assays. One assay used primers 


\section{FIGURE 2}

Average scores ${ }^{\mathrm{a}}$ of cytotoxicity ${ }^{\mathrm{b}}$ in Madin-Darby canine kidney cells inoculated with solutions consisting of varying proportions of ESwab and Eagles minimum essential media

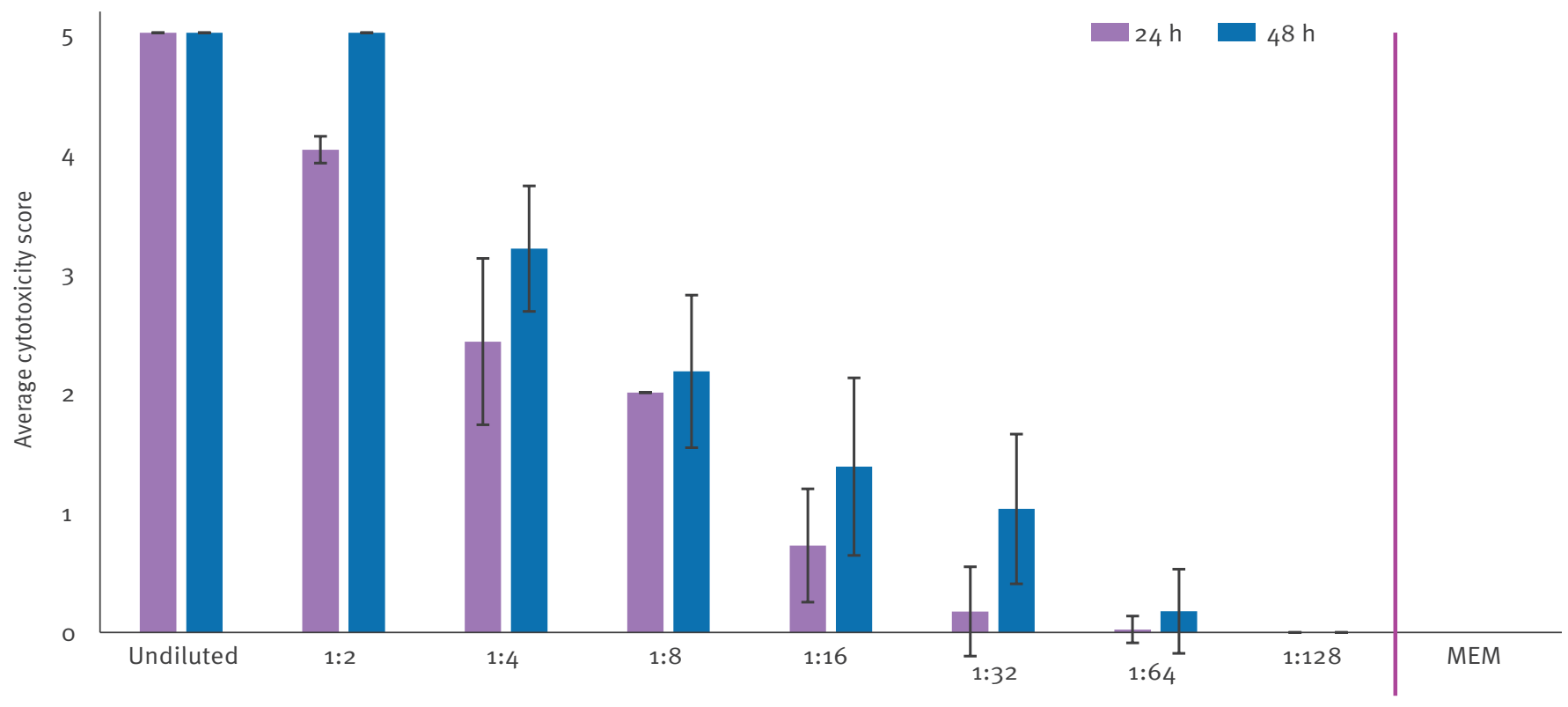

ESwab dilution

MEM: Eagles minimum essential medium.

Twenty ESwab medium solutions were used to generate the eight dilutions shown on the X axis. To evaluate cytotoxicity, Madin-Darby canine kidney cells were inoculated with the 20 replicates for each dilution.

a All dilutions were scored for cytotoxicity after 24 and 48 hours (h) incubation with the Madin-Darby canine kidney cells respectively.

b Cytotoxicity was evaluated by scoring from o to 5 , where o was no toxicity and 5 extensive toxicity. The mean cytotoxicity obtained with replicate experiments is shown on the Figure. Standard deviations are indicated with black bars.

\section{FIGURE 3}

Average scores of cytopathogenic effect ${ }^{\mathrm{a}}$ caused by propagation in Madin-Darby canine kidney cells of influenza virus isolates ${ }^{\mathrm{b}}$ in solutions with varying proportions of ESwab and Eagles minimum essential media

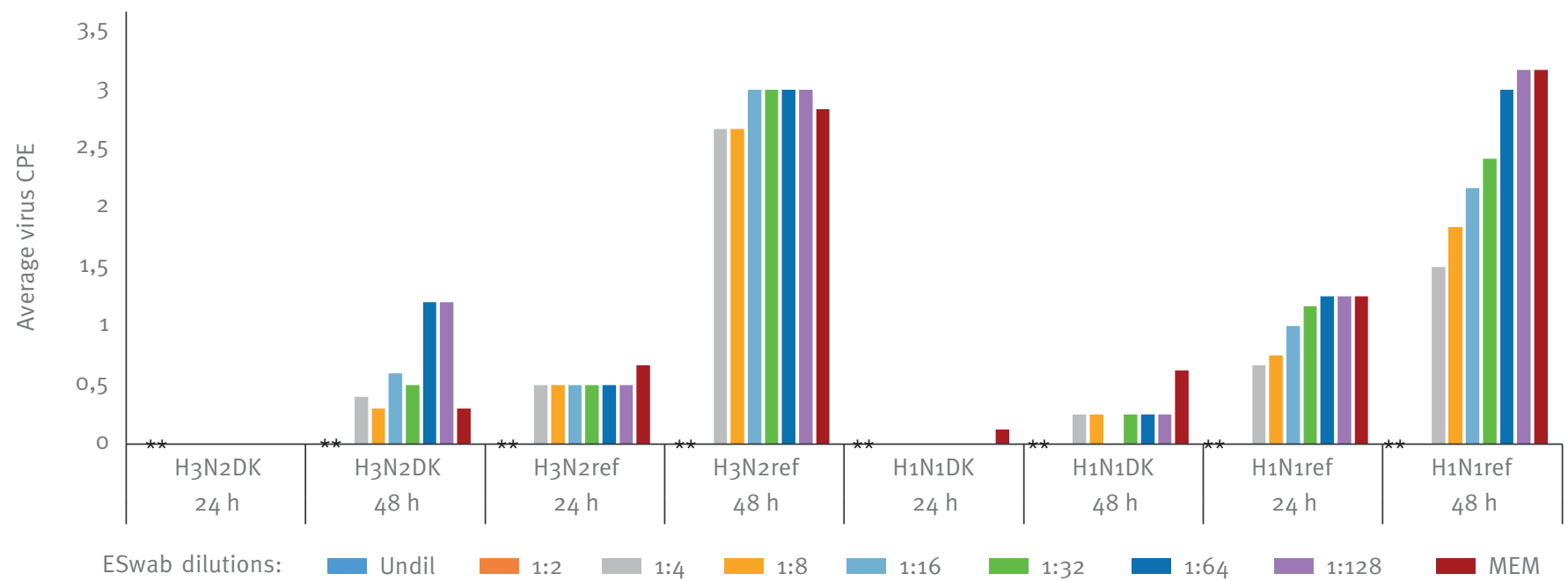

CPE: cytopathogenic effect; MEM: Eagles minimum essential medium; undil: undiluted Eswab medium.

Due to the highly toxic effect of the undiluted and 1:2 dilution of the ESwab medium it was not possible to evaluate influenza virus CPE in these dilutions. This is indicated by asterisks (*) in the Figure.

a CPE was scored from o to 4, where o was no CPE, 1 was up to $25 \%$ CPE, 2: $25-50 \%, 3: 50-75 \%$ and 4: 75-100\% CPE. Scoring was performed after 24 and 48 hours incubation of the inoculated cells. Virus CPE was confirmed by immunostaining of influenza virus infected cells.

b Dilutions of the following influenza virus isolates were used: A/California/07/2009 $\left(\mathrm{H}_{1} \mathrm{~N}_{1} \mathrm{pdmog}\right)\left(\mathrm{H}_{1} \mathrm{~N}_{1} \mathrm{ref}(\mathrm{n}=6)\right)$, A/Denmark/42/2014 $\left(\mathrm{H}_{1} \mathrm{~N}_{1} p d m 09\right)\left(\mathrm{H}_{1} \mathrm{~N}_{1} \mathrm{DK}(\mathrm{n}=4)\right)$, A/Brisbane/10/2007 $\left(\mathrm{H}_{3} \mathrm{~N}_{2}\right)\left(\mathrm{H}_{3} \mathrm{~N}_{2} \mathrm{ref}(\mathrm{n}=3)\right)$, and A/Denmark/43/2014 $\left(\mathrm{H}_{3} \mathrm{~N}_{2}\right)\left(\mathrm{H}_{3} \mathrm{~N}_{2} \mathrm{DK}(\mathrm{n}=5)\right)$. The solutions used to dilute the virus isolates consisted of varying proportions of ESwab medium and Eagles MEM. Control dilutions of the virus isolates were in pure Eagles MEM. 
Results of real-time reverse transcription-polymerase chain reaction depending on the dilution level of H1N1pdm09 reference virus template in ESwab medium or phosphate-buffered saline, with effect of different storage conditions

\begin{tabular}{|c|c|c|c|c|c|c|c|c|c|c|}
\hline \multirow{2}{*}{$\begin{array}{l}\text { Real-time } \\
\text { RT-PCR target }\end{array}$} & \multirow{2}{*}{$\begin{array}{l}\text { Storage time and } \\
\text { temperature }\end{array}$} & \multirow{2}{*}{ Medium } & \multicolumn{8}{|c|}{ Ct values obtained with $\mathrm{A} / \mathrm{California/07/2009}\left(\mathrm{H}_{1} \mathrm{~N}_{1} p d m 09\right)^{\text {a }}$ dilutions } \\
\hline & & & Undiluted & $10^{-1}$ & $10^{-2}$ & $10^{-3}$ & $10^{-4}$ & $10^{-5}$ & $10^{-6}$ & $10^{-7}$ \\
\hline \multirow{8}{*}{ Matrix gene } & \multirow{2}{*}{$24 \mathrm{~h}$ and $4^{\circ} \mathrm{C}$} & ESwab & 19.75 & 22.70 & 26.15 & 29.72 & 32.68 & 35.68 & 41.48 & - \\
\hline & & PBS & 19.48 & 24.21 & 27.67 & 29.56 & 33.29 & 36.18 & 43.67 & - \\
\hline & \multirow{2}{*}{$7 \mathrm{~d}$ and $4^{\circ} \mathrm{C}$} & ESwab & 19.53 & 23.12 & 26.66 & 29.88 & 32.32 & 36.74 & 38.84 & - \\
\hline & & PBS & 20.12 & 25.20 & 26.71 & 31.03 & 33.66 & 37.60 & 39.96 & - \\
\hline & \multirow{2}{*}{$24 \mathrm{~h}$ and $20^{\circ} \mathrm{C}$} & ESwab & 19.95 & 22.26 & 25.97 & 29.31 & 33.36 & 36.12 & 39.98 & - \\
\hline & & PBS & 19.40 & 25.29 & 26.13 & 29.87 & 35.19 & 36.11 & 41.67 & - \\
\hline & \multirow{2}{*}{$7 \mathrm{~d}$ and $20^{\circ} \mathrm{C}$} & ESwab & 20.33 & 23.67 & 27.47 & 31.43 & 32.03 & 37.97 & 38.16 & - \\
\hline & & PBS & 20.15 & 24.90 & 26.09 & 30.16 & 34.30 & 37.70 & - & - \\
\hline \multirow{8}{*}{ N1pdmog gene } & \multirow{2}{*}{$24 \mathrm{~h}$ and $4^{\circ} \mathrm{C}$} & ESwab & 18.95 & 21.68 & 25.83 & 29.16 & 32.36 & 36.50 & 39.52 & - \\
\hline & & PBS & 19.08 & 23.23 & 26.51 & 29.59 & 33.35 & 36.00 & 39.82 & - \\
\hline & \multirow{2}{*}{$7 \mathrm{~d}$ and $4^{\circ} \mathrm{C}$} & ESwab & 18.81 & 22.12 & 26.37 & 29.48 & 32.37 & 36.40 & 39.76 & - \\
\hline & & PBS & 19.56 & 25.53 & 27.82 & 32.24 & 35.22 & - & - & - \\
\hline & \multirow{2}{*}{$24 \mathrm{~h}$ and $20^{\circ} \mathrm{C}$} & ESwab & 18.80 & 21.14 & 25.66 & 29.03 & 32.47 & 35.76 & 37.84 & - \\
\hline & & PBS & 18.93 & 23.97 & 26.00 & 29.60 & 34.02 & 35.40 & 39.90 & - \\
\hline & \multirow{2}{*}{$7 \mathrm{~d}$ and $20^{\circ} \mathrm{C}$} & ESwab & 18.95 & 22.88 & 27.21 & 30.49 & 33.42 & 35.90 & 39.93 & - \\
\hline & & PBS & 19.08 & 25.21 & 27.14 & 31.40 & 35.96 & 38.39 & - & - \\
\hline
\end{tabular}

Ct: cycle threshold; d: days, h: hours; MDCK: Madin-Darby canine kidney cells; PBS: phosphate-buffered saline; RT-PCR: reverse-transcription polymerase chain reaction; sw: primary swine kidney cells; TCID: tissue culture infective dose; -: negative.

a A/California/07/2009 (H1N1pdmo9) (passage history: two times in sw/four times in MDCK) with titre of $2 \times 10^{6} \mathrm{TCID}_{50} / \mathrm{mL}$.

and a probe for the matrix gene of influenza A virus, the other, primers and a probe for the neuraminidase (NA) gene of $\mathrm{H}_{1} \mathrm{~N}_{1}$ pdmo9. The dilution series were stored at $4^{\circ} \mathrm{C}$ for 24 hours or seven days before testing by PCR, this to mimic a realistic time span for samples submitted to the laboratory vs optimal conditions.

\section{Results}

ESwab medium and viral culture

MDCK cells inoculated with undiluted ESwab medium, were completely lysed after 24 hours of incubation and only granulated cell debris was observed (Figure 1 and 2). Cytotoxic effects were observed from dilution 1:2 until 1:32 but were clearly decreasing by each dilution step of the ESwab medium (Figure 1 and 2). The cytotoxic effects were recognised as granulated cell debris from lysed cells, apoptotic cells displaying apoptotic bodies, and irregular cells loosing attachment. After 48 hours the cytotoxic effects were more pronounced and were observed until at a dilution of 1:64, however, with only minor cytotoxicity (mean score: 0.176 ) in this dilution step (Figure 2).

Due to the highly cytotoxic effect of the undiluted and 1:2 dilution of the ESwab medium it was not possible to evaluate influenza virus CPE at these dilutions. However, the success of influenza virus infection, scored by CPE and confirmed by immunostaining, was increasing by each dilution step of the ESwab medium from 1:4 until 1:128 (Figure 3). This finding is most notable for the $\mathrm{H}_{1} \mathrm{~N} 1 \mathrm{pdmog}$ virus isolates.

\section{ESwab medium and real-time reverse}

transcription-polymerase chain reaction

The suitability of the ESwab medium for diagnostics using PCR techniques was confirmed, as the H1N1pdmo9 virus diluted in both ESwab and PBS, respectively, was detected equally well by two different real time RT-PCR assays (Table). In addition to this, the $P C R$ results were not affected by storage of the dilutions series for seven days compared with 24 hours at $4^{\circ} \mathrm{C}$ before PCR testing (Table).

\section{Discussion}

In this study we document that the ESwab medium severely affects the MDCK cells. Cell lysis and apoptosis in such cells suggest that the medium creates hyperosmolarity. The ESwab declaration lists a range of salts included in the medium and a milky appearance suggests high concentrations of salts. The MDCK cells are seemingly unaffected when the ESwab medium is diluted $1: 64$ to $1: 128$ in Eagles minimum essential medium, before inoculation in cells.

In agreement with this, we find that virus propagation is most successful when the medium is diluted substantially. Dilution to this degree is however not an 
option for most clinical samples, as the virus concentration varies greatly between samples, and low virus concentrations are common. The virus isolates, which are used in the experiments described in this report, have been propagated in cell culture beforehand and viral cell adaptation must be expected [10]. Influenza viruses in clinical samples are by nature not adapted to the MDCK cells used for viral propagation, which means that we should expect an even lower success rate.

From our results, we can confirm that samples in ESwab medium are appropriate for diagnostics using real-time RT-PCR, as viral RNA appears unaffected by the otherwise cell toxic ingredients of this medium.

The increased use of ESwab as a multipurpose swab (for bacteria and virus sampling) at the hospitals in Denmark, despite it being intended for bacterial sampling, challenges the national influenza surveillance programme, as lack of successful virus culture prevents antigenic characterisation using haemagglutination inhibition test, as well as functional testing for resistance to antiviral drugs. The phenotypic assays for antigenic characterisation and resistance testing require virus isolates $[1,2,11]$ and important information regarding phenotypic drift, not necessarily recognised by genome sequencing, will be lost. If the increasing trend using the ESwab sampling kit continues, we face a new risk of losing important data on vaccine match and on determination of antiviral treatment failure as well as information on new virus candidates for vaccine formulation.

To exemplify the problem, in the $2013 / 14$ season NIC Denmark received a sample harbouring influenza $A\left(\mathrm{H}_{3} \mathrm{~N}_{2}\right)$ virus. Sequencing revealed, in collaboration with the World Health Organization Collaborating Center for Influenza in London, that the sample was probably antigenically distinct from the otherwise circulating dominant $\mathrm{H}_{3} \mathrm{~N}_{2}$ viruses in Denmark and Europe. At that time only one identical $\mathrm{H}_{3} \mathrm{~N}_{2}$ virus had so far been described in the Global Initiative on Sharing Avian Influenza Data (GISAID). This virus had been identified in an American patient by the World Health Organization Collaborating Center at the United States Centers for Disease Control and Prevention in Atlanta. The sample had been submitted to NIC Denmark in ESwab, preventing the preparation of a virus isolate for phenotypic antigenic characterisation. The opportunity was therefore lost to further explore this strain of concern.

The ESwab medium is highly unfit for viral propagation in cells and to avoid cytoxicity substantial dilution of the medium is required. This in practice is feasible only with the few samples containing high viral loads. Feedback from the hospitals in Denmark upon request from the Danish NIC to change the medium to a virusfriendly medium, is that the ESwab sampling kit is convenient because it is useful for PCR [7], and the staff only need to relate to one sampling material. Another argument is that the ESwab is also cheaper than the available universal/viral transport media (UTM/ VTM). Therefore, most regional clinical microbiology departments so far have not changed medium. As a consequence, the Danish NIC has kindly requested twin-samples to be collected from the critically ill patients highly suspected for influenza disease during the coming 2014/15 influenza season. Feedback when informally addressing the challenges experienced in Denmark at international influenza meetings and virus symposia during 2014 has led us to believe that the increased use of ESwab may also be occurring in other European countries and we therefore expect our findings to have implications for the influenza surveillance of such countries.

\section{Conclusion}

The results from this study expand our understanding further of the cytotoxic effect of the ESwab sampling kit on cells used to propagate viruses, and indicate that whereas the ESwab sampling kit can be used for virus diagnostic purposes using RT-PCR, it is highly unfit for viral propagation in cell cultures and the continuing widespread use of the ESwab may pose difficulties for influenza surveillance.

\section{Acknowledgements}

For technical assistance in the laboratory Kristine Vorborg, National Influenza Center Denmark, Statens Serum institute, Artillerivej 5, 2300 Copenhagen S, Denmark. Work at the WHO Collaborating Centre in London is supported by the Medical Research Council programme number U117512723.

\section{Conflict of interest}

None declared.

Authors' contributions

RT: Conceived and designed the experiments in collaboration with BA and TKF, analysed the data, and wrote the paper. BA and JR: Performed the experiments, and analysed the data. JM: Contributed to discussion and information regarding the ESwab sampling kit as well as antigenic analysis perspectives. TKF: Contributed further with discussion of data and perspectives, as well as reviewing of the paper. All authors have seen, commented, and approved the paper.

\section{References}

1. Klimov A, Balish A, Veguilla V, Sun H, Schiffer J, Lu X, et al. Influenza virus titration, antigenic characterization, and serological methods for antibody detection. Methods Mol Biol. 2012;865:25-51. http://dx.doi.org/10.1007/978-1-61779-621O_3 PMID:22528152

2. Wetherall NT, Trivedi T, Zeller J, Hodges-Savola C, McKimmBreschkin JL, Zambon M, et al. Evaluation of neuraminidase enzyme assays using different substrates to measure susceptibility of influenza virus clinical isolates to neuraminidase inhibitors: report of the neuraminidase inhibitor susceptibility network. J Clin Microbiol. 2003;41(2):74250. http://dx.doi.org/10.1128/JCM.41.2.742-750.2003 PMID:12574276 
3. Bragstad K, Emborg H, Fischer TK, Voldstedlund M, Gubbels S, Andersen $B$, et al. Low vaccine effectiveness against influenza $A\left(\mathrm{H}_{3} \mathrm{~N}_{2}\right)$ virus among elderly people in Denmark in 2012/13- a rapid epidemiological and virological assessment. Euro Surveill. 2013;18(6). PMID:23410258

4. Tan TY, Ng LS, Sim DM, Cheng Y, Min MO. Evaluation of bacterial recovery and viability from three different swab transport systems. Pathology. 2014;46(3):230-3. http://dx.doi. org/10.1097/PAT.0000000000000074 PMID:24614721

5. Van Horn KG, Audette CD, Sebeck D, Tucker KA. Comparison of the Copan ESwab system with two Amies agar swab transport systems for maintenance of microorganism viability. I Clin Microbiol. 2008;46(5):1655-8. http://dx.doi.org/10.1128/ JCM.02047-07 PMID:18353935

6. Van Horn KG, Audette CD, Tucker KA, Sebeck D. Comparison of 3 swab transport systems for direct release and recovery of aerobic and anaerobic bacteria. Diagn Microbiol Infect Dis. 2008;62(4):471-3. http://dx.doi.org/10.1016/j. diagmicrobio.2008.08.004 PMID:18814991

7. Druce J, Garcia K, Tran T, Papadakis G, Birch C. Evaluation of swabs, transport media, and specimen transport conditions for optimal detection of viruses by PCR. J Clin Microbiol. 2012;50(3):1064-5. http://dx.doi.org/10.1128/JCM.06551-11 PMID:22205810

8. Silbert S, Kubasek C, Uy D, Widen R. Comparison of ESwab with traditional swabs for detection of methicillin-resistant Staphylococcus aureus using two different walk-away commercial real-time PCR methods. Comparison of ESwab with traditional swabs for the detection of methicillinresistant Staphylococcus aureus using two different walkaway commercial real-time PCR methods. J Clin Microbiol. 2014;52(7):2641-3. http://dx.doi.org/10.1128/JCM.00315-14 PMID:24759722

9. Indevuyst C, Beuselinck K, Lagrou K. ESwab flocked swabs unfit for viral culture. J Clin Virol. 2012;55(3):282-3. http:// dx.doi.org/10.1016/j.jcv.2012.07.006 PMID:22858119

10. Zhirnov OP, Vorobjeva IV, Saphonova OA, Poyarkov SV, Ovcharenko AV, Anhlan D, et al. Structural and evolutionary characteristics of HA, NA, NS and M genes of clinical influenza $\mathrm{A} / \mathrm{H}_{3} \mathrm{~N}_{2}$ viruses passaged in human and canine cells. Clin Virol. 2009;45(4):322-33. http://dx.doi.org/10.1016/j. jcv.2009.05.030 PMID:19546028

11. Duwe SC, Wedde M, Birkner P, Schweiger B. Genotypic and phenotypic resistance of pandemic $A / \mathrm{H}_{1} \mathrm{~N}_{1}$ influenza viruses circulating in Germany. Antiviral Res. 2011;89(1):115-8. http:// dx.doi.org/10.1016/j.antiviral.2010.11.001 PMID:21070812> 